\title{
Ecotoxicological characterization of photoelectrocatalytic process for degradation of pentachlorophenol on titania nanotubes electrode
}

\author{
Wei Liu ${ }^{\mathrm{a}}$, Xie Quan ${ }^{\mathrm{a}, *}$, Qing Cui ${ }^{\mathrm{b}}$, Mei Ma ${ }^{\mathrm{b}}$, Shuo Chen ${ }^{\mathrm{a}}$, Zi-Jian Wang ${ }^{\mathrm{b}}$ \\ ${ }^{a}$ School of Environmental and Biological Science and Technology, Dalian University of Technology, \\ Key Laboratory of Industrial Ecology and Environmental Engineering, Ministry of Education, Dalian 116024, China \\ ${ }^{\mathrm{b}}$ State Key Laboratory of Environmental Aquatic Chemistry, Research Center for Eco-Environmental Sciences, Chinese Academy of Sciences, \\ Beijing 100085, China
}

Received 3 November 2006; received in revised form 8 July 2007; accepted 4 August 2007

Available online 19 September 2007

\begin{abstract}
Luminescence bioassay using Vibrio fischeri and in vitro ethoxyresorufin-O-deethylase (EROD) induction bioassay using H4-IIE rat hepatoma cell were employed to test toxicity changes during the photoelectrocatalysis process for the degradation of pentachlorophenol (PCP) on $\mathrm{TiO}_{2}$ nanotubes electrode. Acute toxicity of the reaction solution reduced by $83 \%$ after 120 min of irradiation. Bioassayderived 2,3,7,8-TCDD equivalents (TEQ ${ }_{\text {bio }}$ ) increased from 0.72 to $6.72 \mathrm{ng}^{-1}$ during the former reaction stage, decreasing rapidly to $1.25 \mathrm{ng}^{-1}$ during the latter reaction stage. HRGC/HRMS analysis detected polychlorinated dibenzo- $p$-dioxins/dibenzofurans (PCDD/ Fs) congeners in the reaction mixtures. TEQ ${ }_{\text {bio }}$ and chemical-derived 2,3,7,8-TCDD equivalents (TEQ cal) were about of the same order of magnitude. Both results illustrated the formation of dioxins and their removal by photoelectrocatalysis. Moreover, photoelectrocatalysis showed a significant priority over direct photolysis and photocatalysis depending on the reaction conditions, not only for PCP removal but also for reduction in toxicity.
\end{abstract}

(C) 2007 Elsevier Inc. All rights reserved.

Keywords: Photoelectrocatalysis; Pentachlorophenol; Luminescent bacteria; EROD induction; Dioxin; Environmental safety

\section{Introduction}

The heterogeneous photocatalytic oxidation process using titanium dioxide $\left(\mathrm{TiO}_{2}\right)$ as photocatalyst has been studied as an emerging successful advanced oxidation process (AOP) to remove trace amounts of refractory organic contaminants in wastewater (Crittenden et al., 1997). When a biasing potential was introduced into the photocatalytic process, which is referred to photoelectrocatalysis (Vinodgopal et al., 1993; Kim and Anderson, 1994), the recombination of electron/hole pairs was reduced. Furthermore, $\mathrm{TiO}_{2}$-based nanotubes began to attract wide attention because of the large surface area and corresponding potentials in many areas. Hence, when the supported $\mathrm{TiO}_{2}$ nanotubes were used as working electrode

\footnotetext{
${ }^{*}$ Corresponding author. Fax: + 8641184706263

E-mail address: quanxie@dlut.edu.cn (X. Quan).
}

in the photoelectrocatalysis system, the oxidation efficiency will be further improved (Quan et al., 2005).

Pentachlorophenol (PCP) has many uses in agriculture and industry as an important component part of fungicides, bactericides, insecticides, and wood preservatives (Keith and Telliard, 1979). The wide use of PCP, as well as its improper disposal in landfills and in low-temperature combustion, contributes significantly to contamination of the environment (Ho and Bolton, 1998). Moreover, PCP is one of the simple and typical polychlorinated aromatic hydrocarbons, investigation on which is of important referential value for other polychlorinated compounds.

When classifying the efficacy of an advanced oxidation process, removal of the target compound or the total organic carbon (TOC) was used as the performance indicator in most studies. These parameters were not sufficient used on their own, since the formation of transient organic compounds, some of them more toxic than the starting one, should also be monitored (Köhler et al., 2006). 
For example, polychlorinated dibenzo-p-dioxins/dibenzofurans $(\mathrm{PCDD} / \mathrm{Fs})$ have been detected in the direct photolysis process of PCP in both aqueous solution and solid matrices (Lamparski et al., 1980; Vollmuth et al., 1994), which are obviously more toxic than PCP. There were also some studies related to the toxicity evaluation for the direct photolysis of PCP (Jardim et al., 1997; Manilal et al., 1992). However, little is known hitherto about the ecotoxicological characteristics of the photoelectrocatalysis process for PCP removal. Moreover, acute toxicity was the only toxicity indicator in most related studies, which may be not sensitive enough to detect the low dose dangerous compounds. Hence, further investigation using more sensitive or specific toxicity indicator was warranted.

The bioluminescence inhibition assay with Vibrio fischeri is used worldwide to evaluate the toxicological effect of effluents and wastewaters due to its high sensitivity and perform simplicity (Pintar et al., 2004; Wang et al., 2002). The induction of ethoxyresorufin- $O$-deethylase (EROD) activity in the cell lines containing an inducible cytochrome P4501A (CYP1A) system, such as H4IIE rat hepatoma cell, fish liver cell line, and others, is the aryl hydrocarbon (Ah) receptor (AhR)-specific response that has been used extensively as a biomarker to characterize the existence of AhR agonists in the complex mixture system. These include PCDD/Fs, polycyclic aromatic hydrocarbons (PAHs), and polychlorinated biphenyls (PCBs) type of pollutants (Hilscherova et al., 2000).

Bioassays and chemical analysis were used in combination in this study to investigate the photoelectrocatalysis process of PCP. The purposes of this study are: (1) serve for the evaluation of the environmental safety of this process; (2) compare the efficiency of photoelectrocatalysis for the removal of PCP and its toxic products with direct photolysis and photocatalysis processes for the assessment of the feasibility of photoelectrocatalysis as an alternative method for the treatment of such recalcitrant compounds.

\section{Materials and methods}

\subsection{Photoelectrocatalytic experiment}

PCP is of analytical grade from Tianjin NanKai Chemical Company (China). The photoelectrocatalytic degradation was performed in a single photoelectrochemical compartment, mainly comprised of a quartz reactor (effective volume: $125 \mathrm{ml}$ ), an ultraviolet light source and a potentiostat. The potentiostat was connected with a counter electrode (Pt sheet), a working electrode (a supported $\mathrm{TiO}_{2}$ nanotubes electrode) and a reference electrode (a saturated calomel electrode, SCE). Details for the preparation of $\mathrm{TiO}_{2}$ nanotubes electrode and the reactor system were described elsewhere (Quan et al., 2005). The experiment was carried out under the following conditions: UV irradiation (a $300 \mathrm{~W}$ high-pressure mercury lamp from the factory of Shanghai YaMing Light with a maximum wavelength of $365 \mathrm{~nm}$ ), vigorous stirring, $0.2 \mathrm{~V}$ (vs. SCE) of electric bias, $0.01 \mathrm{M}$ sodium sulfate as electrolyte, and no airflow. In the case of direct photolysis, experiments were performed in the same reactor only with a UV irradiation. Photocatalytic degradation of PCP was also carried out in the same reactor with UV irradiation and the supported $\mathrm{TiO}_{2}$ nanotubes as photocatalyst.
PCP concentration was analyzed by HPLC (PU-1580, UV-1575, Jasco Corporation, Japan) with a Kromasil ODS $(5 \mu \mathrm{m}, 4.6 \mathrm{~mm} \times 250 \mathrm{~mm})$ reverse-phase column. The mobile phase was $1.0 \mathrm{ml} \mathrm{min}^{-1}$ of methanol and water $(1 \% \operatorname{HAc}(\mathrm{v} / \mathrm{v}))(\mathrm{v} / \mathrm{v}=85: 15)$ and the detector wavelength was set as $254 \mathrm{~nm}$.

\subsection{Sample pretreatment procedure}

The samples for bioassay were concentrated by solid-phase extraction using HLB Oasis cartridges ( $200 \mathrm{mg}$, Waters, USA). Before bioassay, the samples were eluted by $5 \mathrm{ml}$ hexane:dichloromethane $(\mathrm{v} / \mathrm{v}=1: 1)$ and $5 \mathrm{ml}$ dichloromethane:methanol $(\mathrm{v} / \mathrm{v}=9: 1)$ serially. Then the eluates were evaporated to dryness with gentle stream of nitrogen and dissolved in dimethyl sulphoxide (DMSO) (Sigma). Procedural blank using de-ionized water was run alongside the samples as an assay control. All the solvents were of HPLC grade from Dima Technology Inc.

\subsection{Bioluminescence test}

The luminescent bacteria $V$. fischeri were purchased as freeze-dried reagents. They were stored at $-20^{\circ} \mathrm{C}$ and hydrated prior to testing. The $15 \mathrm{~min}$ standard bioluminescence inhibition assay was carried out according to ISO 11348-2 (1994) and DIN 38412 L34/L341 (1997). Luminescence inhibition was calculated by a comparison of the light with control measured under the same condition. Bioluminescence was measured on a luminometer (Lumat LB9501, Berhold Co.). $\mathrm{NaCl}$ was used for osmotic adjustments. All bioassays were carried out at $T=16 \pm 1^{\circ} \mathrm{C}$, with a $15 \mathrm{~min}$ contact time with samples. For reaction product mixtures, the concentrations of samples were expressed as percent by volume, so did the median effective concentration $\left(\mathrm{EC}_{50}\right)$ value. All samples were tested in five concentrations and each concentration was tested in triplicate. We can define a relative toxicity index (RTI) from the toxic unit (TU) as

$\mathrm{TU}=\frac{1}{\mathrm{EC}_{50}}$,

$\mathrm{RTI}=\frac{\mathrm{TU}_{t}}{\mathrm{TU}_{0}}$,

where $\mathrm{TU}_{0}$ is the $\mathrm{TU}$ of the reaction solution at time $t=0$, and $\mathrm{TU}_{t}$ is the TU of the reaction solution at time $t$.

\subsection{In vitro EROD induction bioassay}

The cell culture and EROD assay were carried out according to Donato et al. (1993) and Ma et al. (2005). Briefly, the H4-IIE rat hepatoma cell line was maintained in a humidified, $5 \% \mathrm{CO}_{2}$ atmosphere at $37^{\circ} \mathrm{C}$. Dulbecco's modified eagle medium (DMEM, GiBCO, Germany) containing $3.7 \mathrm{gl}^{-1}$ $\mathrm{NaHCO}_{3}$ was supplemented with $10 \%$ fetal bovine serum, 100 units $\mathrm{ml}^{-1}$ penicillin and $100 \mathrm{\mu g} \mathrm{ml}^{-1}$ streptomycin and used as cell culture medium. H4-IIE cells $\left(1.5 \times 10^{4}\right.$ cells ml $\left.^{-1}\right)$ were first seeded into individual wells of a 96-well tissue culture plate in $0.1 \mathrm{ml}$ of medium, and the medium were refreshed with medium containing test samples after $24 \mathrm{~h}$. Six concentration levels were chosen for test. The final concentration of DMSO was less than $0.5 \%$, which showed no toxic effect on the cells. The same amount of the organic solvent was added to control cultures. 2,3,7,8-TCDD standard solutions were included on each plate as positive controls and for calibration purposes.

After incubation of $72 \mathrm{~h}$, EROD enzyme activity was determined directly in intact rat hepatoma cell cultured on 96-well plates as in Donato's method (Donato et al., 1993). Assay was started by the addition of $100 \mu \mathrm{l}$ well $^{-1}$ of culture medium containing 7-ethoxyresorufin $(1 \mathrm{mM})$ as substrate and dicumarol $(10 \mu \mathrm{M})$ to prevent further metabolism of the resorufin formed by the cytosolic enzyme diaphorase. The reaction was stopped by adding $130 \mu \mathrm{l}$ methanol to each well after $60 \mathrm{~min}$. A $100 \mu \mathrm{l}$ aliquot of cell medium was withdrawn from each well and transferred to another 96-well plate. Fluorescence of the product resorufin was recorded 
directly on Microplate Reader (TECAN-GENios, Australia) at $535 \mathrm{~nm}$ excitation and $590 \mathrm{~nm}$ emission wavelengths. The quantification of protein was performed according to the method of Bradford (1976). EROD activity was expressed as picomoles per minute per milligram of microsomal protein. A sigmoid nonlinear curve-fitting module was applied for the dose-response curves of 2,3,7,8-TCDD. The function is a fourparameter logistic equation described by Qiao et al. (2006). TEQ bio was calculated by interpolating the EROD activity induced by the sample in the dose-response curve of 2,3,7,8-TCDD on the same plate.

\subsection{Chemical analysis for PCDD/Fs}

Samples photoelectrocatalized under the given conditions $\left(I_{0}=600 \mu \mathrm{W} \mathrm{cm}{ }^{-2}, C_{0}=20 \mathrm{mg}^{-1}\right)$ were assayed by HRMS/HRGC for $\mathrm{PCDD} / \mathrm{Fs}$ congeners. Several representative samples were selected instead of a cost analysis for all the samples. Sample photoelectrocatalized for 40 min was chosen representative of samples with high potential risk as detected by bioassay. The starting PCP solution was analyzed because PCP can contain PCDD/Fs impurities (Pfeiffer et al., 1978). Sample photoelectrocatalized for $120 \mathrm{~min}$ was analyzed to ensure the removal of the PCDD/Fs. The sample extraction and PCDD/Fs analysis were carried out following US EPA Method 1613 protocols (1994). All the samples were spiked with ${ }^{13} \mathrm{C}$-labeled PCDD/Fs standards before extraction and cleanup. The samples were extracted three times by dichloromethane. Then the extract was cleaned up by acid silica gel, basic alumina (ICN Medical, Germany) and florisil columns (Merck, Germany). An Autospec Ultima high-resolution mass spectrometer (Micromass, UK) interfaced with a Hewlett-Packard (Palo Alto, CA, USA) 6890 plus gas chromatograph was used. Details of the analysis were described by Ni et al. (2005). Quantitative determination was performed by the isotope dilution method based on the relative response factors. This study dealt with tetra- to octachlorinated dioxins and furans. Chemical-derived 2,3,7,8-TCDD equivalents $\left(\right.$ TEQ $\left._{\mathrm{cal}}\right)$ were obtained as the sum of TEQ for an individual compound by assuming additive responses of chemicals in the mixture. TEQ of individual PCDD/Fs chemical was the products of the measured concentrations and the corresponding toxic equivalence factors (I-TEFs). I-TEFs used in this study were according to NATO/CCMS (1988).

\section{Results}

\subsection{Removal of PCP by photoelectrocatalysis, direct photolysis, and photocatalysis}

Removal of PCP by photoelectrocatalysis, direct photolysis, and photocatalysis are compared in Fig. 1. Under the given conditions (irradiation intensity $\left(I_{0}\right)=600 \mu \mathrm{W} \mathrm{cm}{ }^{-2}$, initial PCP concentration $\left.\left(C_{0}\right)=20 \mathrm{mgl}^{-1}\right)$, the photoelectrocatalysis process achieved a PCP removal of $94 \%$ after $120 \mathrm{~min}$ of irradiation. PCP removal decreased as the irradiation intensity decreased $\left(I_{0}=300 \mu \mathrm{W} \mathrm{cm}^{-2}\right)$ or the initial PCP concentration increased $\left(C_{0}=40 \mathrm{mg}^{-1}\right)$, with removal of $76.7 \%$ and $73.0 \%$, respectively.

Direct photolytic and photocatalytic process achieved rather lower removal than photoelectrocatalytic process under identical irradiation intensity and initial PCP concentration, in which the PCP removal was $65.2 \%$ and $79.1 \%$ after $120 \mathrm{~min}$ of irradiation, respectively.

\subsection{Acute toxicity to $V$. fischeri}

As Fig. 2 shows, after $120 \mathrm{~min}$ of photoelectrocatalysis under the given conditions $\left(I_{0}=600 \mu \mathrm{W} \mathrm{cm}{ }^{-2}\right.$,

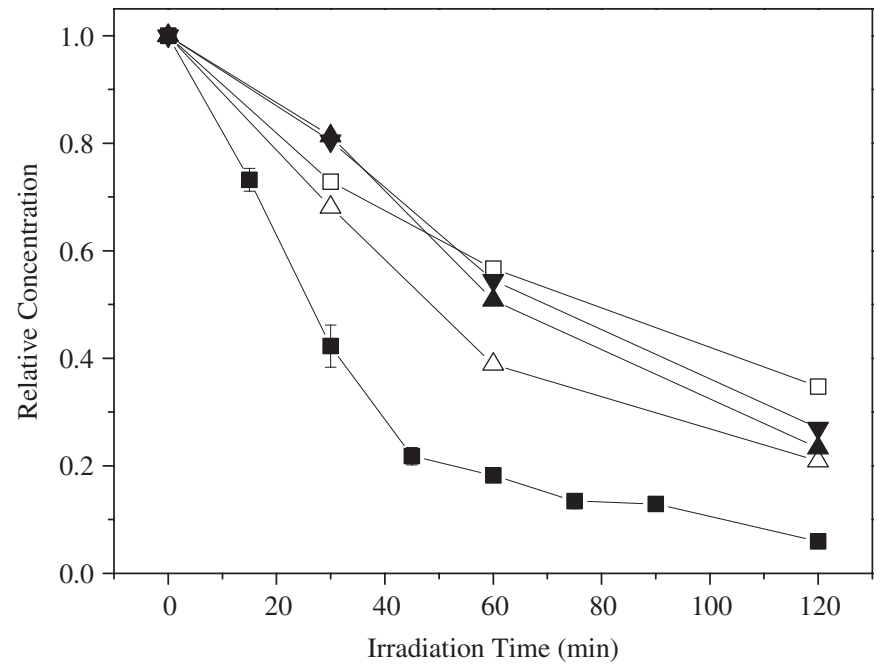

Fig. 1. Changes in PCP concentration during photoelectrocatalysis $(\boldsymbol{\Lambda}$ : $I_{0}=300 \mu \mathrm{W} \mathrm{cm}{ }^{-2}, C_{0}=20 \mathrm{mg} \mathrm{l}^{-1} ; \boldsymbol{\nabla}: I_{0}=600 \mu \mathrm{W} \mathrm{cm}{ }^{-2}, C_{0}=40 \mathrm{mgl}^{-1}$; 口: $\left.I_{0}=600 \mu \mathrm{W} \mathrm{cm}{ }^{-2}, \quad C_{0}=20 \mathrm{mgl}^{-1}\right)$, direct photolysis $\left(\square: I_{0}=\right.$ $\left.600 \mu \mathrm{W} \mathrm{cm}{ }^{-2}, C_{0}=20 \mathrm{mg}^{-1}\right)$, and photocatalysis $\left(\triangle: I_{0}=600 \mu \mathrm{W} \mathrm{cm}^{-2}\right.$, $C_{0}=20 \mathrm{mgl}^{-1}$ ) processes of PCP. Points represent mean value of triplicate samples at each time, bars represent standard errors.

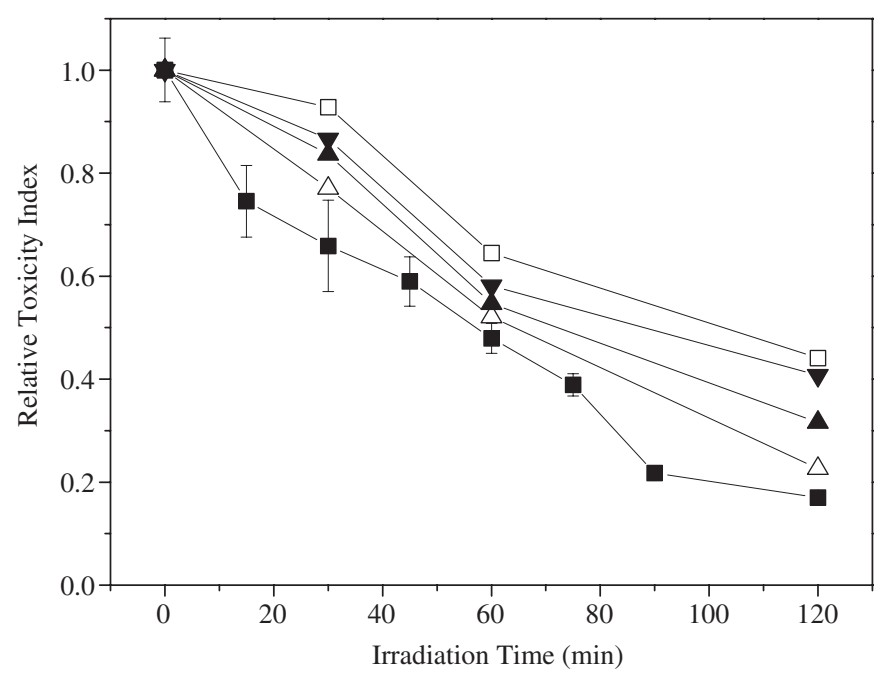

Fig. 2. Changes in acute toxicity during photoelectrocatalysis ( $\mathbf{\Delta}$ : $I_{0}=300 \mu \mathrm{W} \mathrm{cm}{ }^{-2}, C_{0}=20 \mathrm{mg} \mathrm{l}^{-1} ; \mathbf{\nabla}: I_{0}=600 \mu \mathrm{W} \mathrm{cm}{ }^{-2}, C_{0}=40 \mathrm{mgl}^{-1}$; 口: $\left.I_{0}=600 \mu \mathrm{W} \mathrm{cm}^{-2}, C_{0}=20 \mathrm{mgl}^{-1}\right)$, direct photolysis $\left(\square: I_{0}=\right.$ $\left.600 \mu \mathrm{W} \mathrm{cm}{ }^{-2}, C_{0}=20 \mathrm{mgl}^{-1}\right)$, and photocatalysis $\left(\triangle: I_{0}=600 \mu \mathrm{W} \mathrm{cm}^{-2}\right.$, $C_{0}=20 \mathrm{mg} \mathrm{l}^{-1}$ ) processes of PCP.

$\left.C_{0}=20 \mathrm{mgl}^{-1}\right)$, relative toxicity index of the reaction solution determined by bioluminescence test reduced by $83 \%$. When the irradiation intensity decreased $\left(I_{0}=\right.$ $300 \mu \mathrm{W} \mathrm{cm}^{-2}$ ) or the initial PCP concentration increased $\left(C_{0}=40 \mathrm{mgl}^{-1}\right)$, the acute toxicity removal decreased, reducing by $68.4 \%$ and $59.3 \%$, respectively. The acute toxicity removal by direct photolytic and photocatalytic process were lower than photoelectrocatalytic process under identical irradiation intensity and initial PCP concentration, with relative toxicity index reducing by $55.9 \%$ and $77.4 \%$, respectively. 


\subsection{In vitro EROD induction}

During the photoelectrocatalytic process of PCP under the given conditions $\left(I_{0}=600 \mu \mathrm{W} \mathrm{cm}{ }^{-2}, C_{0}=20 \mathrm{mgl}^{-1}\right)$, $\mathrm{TEQ}_{\text {bio }}$ increased from 0.72 to $5.74 \mathrm{ng}^{-1}$ in the initial $15 \mathrm{~min}$, and then remained nearly constant at $20-75 \mathrm{~min}$, reaching maximum of $6.72 \mathrm{ng}^{-1}$ at $45 \mathrm{~min}$, finally reduced to $1.25 \mathrm{ng}^{-1}$ after $120 \mathrm{~min}$ of irradiation (Fig. 3a).

Under identical irradiation intensity and initial PCP concentration, the $\mathrm{TEQ}_{\mathrm{bio}}$ for the samples treated by direct photolytic and photocatalytic process for $120 \mathrm{~min}$ were 2.21 and $2.06 \mathrm{ng}^{-1}$, respectively (Fig. 3b), higher than the samples treated by photoelectrocatalysis process $\left(1.25 \mathrm{ngl}^{-1}\right)$.

For the photoelectrocatalysis process, when the irradiation intensity decreased $\left(I_{0}=300 \mu \mathrm{W} \mathrm{cm}{ }^{-2}\right)$ or the initial PCP concentration increased $\left(C_{0}=40 \mathrm{mg}^{-1}\right)$, the EROD induction activity of the reaction solutions significantly

a

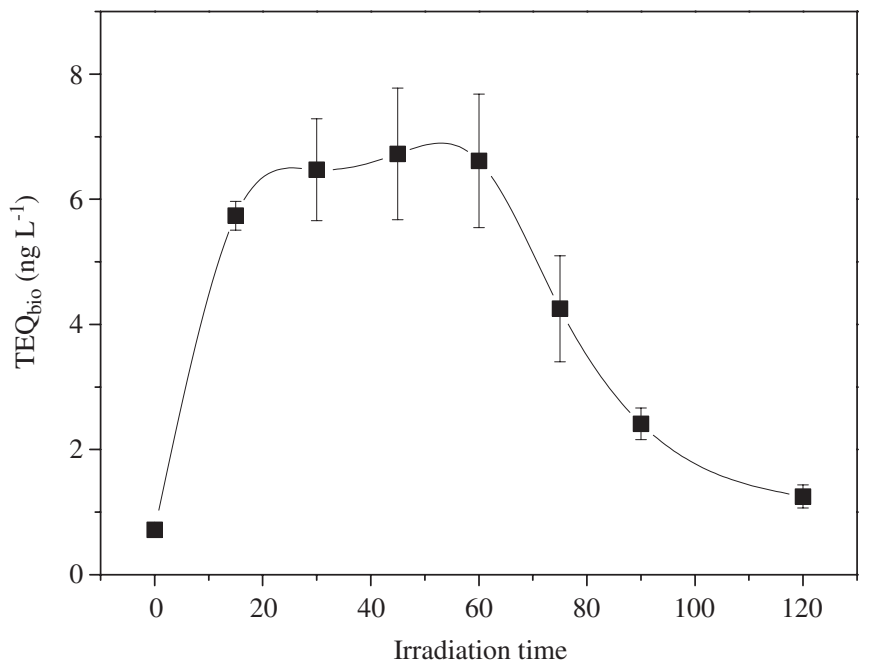

b

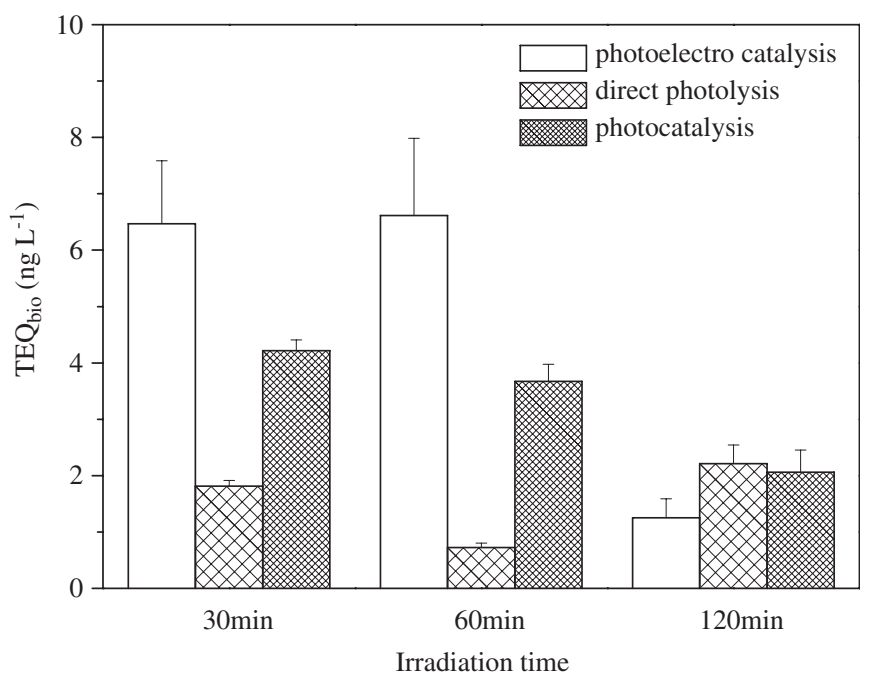

Fig. 3. Changes in $\mathrm{TEQ}_{\text {bio }}$ during photoelectrocatalysis (a) and comparisons of TEQ $\mathrm{bio}_{\text {io }}$ in different processes (b). $I_{0}=600 \mu \mathrm{W} \mathrm{cm}{ }^{-2}, C_{0}=20 \mathrm{mg} \mathrm{l}^{-1}$.

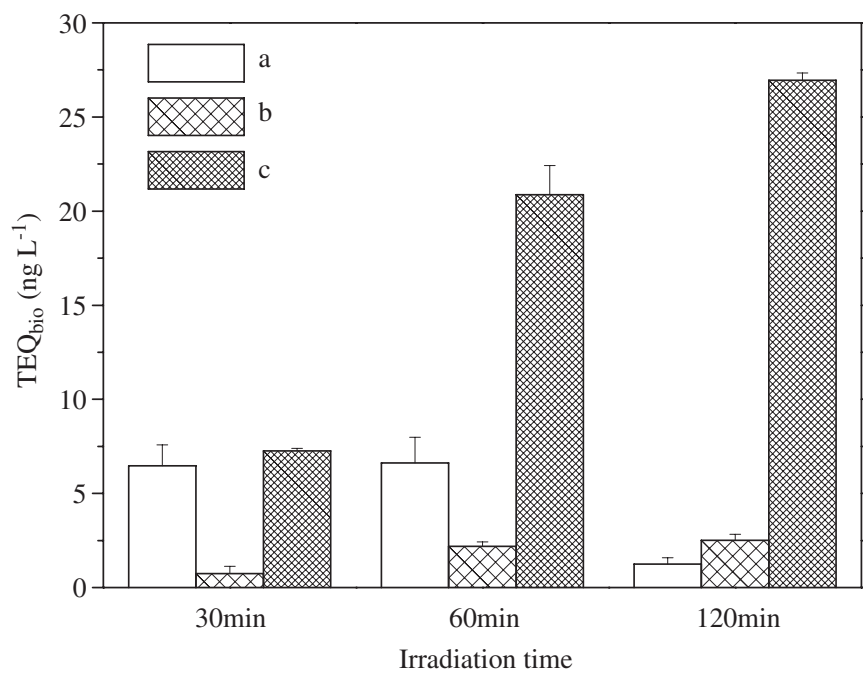

Fig. 4. Changes in $\mathrm{TEQ}_{\text {bio }}$ during photoelectrocatalysis process under different reaction conditions. (a) $I_{0}=600 \mu \mathrm{W} \mathrm{cm} \mathrm{cm}^{-2}, C_{0}=20 \mathrm{mg} \mathrm{l}^{-1}$; (b) $I_{0}=300 \mu \mathrm{W} \mathrm{cm}{ }^{-2}, C_{0}=20 \mathrm{mgl}^{-1}$; and (c) $I_{0}=600 \mu \mathrm{W} \mathrm{cm}{ }^{-2}, C_{0}=$ $40 \mathrm{mg} \mathrm{l}^{-1}$.

increased, especially under the latter condition (Fig. 4). $\mathrm{TEQ}_{\text {bio }}$ increased to 2.51 and $26.95 \mathrm{ng}^{-1}$, respectively, after $120 \mathrm{~min}$ of irradiation in those two processes.

\section{4. $P C D D / F$ s concentration}

The concentrations of $17 \mathrm{PCDD} / \mathrm{Fs}$ congeners that elicit 2,3,7,8-TCDD-like toxic effects during the photoelectrocatalysis process of PCP are presented in Table 1. Both PCDDs and PCDFs were detected in the samples. The starting PCP solution contained minor PCDD/Fs due to the impurities in the PCP chemical. A significant increase in $\mathrm{PCDD} / \mathrm{Fs}$ concentrations (congener totals) was observed at $40 \mathrm{~min}$. While concentrations of most of the PCDD/Fs chemicals decreased at $120 \mathrm{~min}$, OCDD concentration was the highest among the congeners at 40 and $120 \mathrm{~min}$ in the reaction solutions. But OCDD contributed only about $1 \%$ to the overall $\mathrm{TEQ}_{\mathrm{cal}}$ due to its low I-TEF. While 1,2,3,4,7,8-HxCDD kept at highest toxicity level, contributing about $30 \%$ to the overall TEQ ${ }_{c a l}$ at 0,40 , and $120 \mathrm{~min}$.

\section{Discussion}

\subsection{Degradation efficiency of PCP by} photoelectrocatalysis, direct photolysis, and photocatalysis

PCP could be effectively removed in the photoelectrocatalysis process and photoelectrocatalysis was more effective for the removal of PCP than direct photolysis and photocatalysis. This result was consistent with the observation of Quan et al. (2005) that there was a significant synergetic effect between the electrochemical process and the photocatalytic process. It is possible that 
Table 1

$\mathrm{PCDD} /$ Fs concentration and $\mathrm{TEQ}_{\mathrm{cal}}\left(\mathrm{ng}^{-1}\right)$ during the photoelectrocatalysis process of PCP

\begin{tabular}{|c|c|c|c|c|c|c|c|}
\hline \multirow[t]{2}{*}{ Chemical } & \multirow[t]{2}{*}{ I-TEF } & \multicolumn{2}{|l|}{$0 \mathrm{~min}$} & \multicolumn{2}{|l|}{$40 \mathrm{~min}$} & \multicolumn{2}{|l|}{$120 \mathrm{~min}$} \\
\hline & & Concentration & $\mathrm{TEQ}_{\mathrm{cal}}$ & Concentration & TEQ $_{\text {cal }}$ & Concentration & $\mathrm{TEQ}_{\mathrm{cal}}$ \\
\hline \multicolumn{8}{|l|}{ PCDD } \\
\hline $2,3,7,8-\mathrm{TCDD}$ & 1 & 0.140 & 0.140 & 0.095 & 0.095 & 0.029 & 0.029 \\
\hline $1,2,3,7,8-\mathrm{PeCDD}$ & 0.5 & 0.207 & 0.103 & 0.348 & 0.174 & $9.351 \mathrm{E}-03$ & $4.676 \mathrm{E}-03$ \\
\hline $1,2,3,4,7,8-\mathrm{HxCDD}$ & 0.1 & 4.964 & 0.496 & 2.836 & 0.284 & 1.117 & 0.112 \\
\hline $1,2,3,6,7,8-\mathrm{HxCDD}$ & 0.1 & 0.168 & 0.017 & 1.603 & 0.160 & 0.145 & 0.015 \\
\hline $1,2,3,7,8,9-\mathrm{HxCDD}$ & 0.1 & 0.049 & $4.894 \mathrm{E}-03$ & 0.187 & 0.019 & 0.153 & 0.015 \\
\hline $1,2,3,4,6,7,8-\mathrm{HpCDD}$ & 0.01 & 5.377 & 0.054 & 4.861 & 0.049 & 2.911 & 0.029 \\
\hline OCDD & 0.001 & 1.420 & $1.420 \mathrm{E}-03$ & 14.917 & 0.015 & 5.395 & $5.395 \mathrm{E}-03$ \\
\hline \multicolumn{8}{|l|}{ PCDF } \\
\hline $2,3,7,8-\mathrm{TCDF}$ & 0.1 & 0.013 & $1.360 \mathrm{E}-03$ & 0.015 & $1.500 \mathrm{E}-03$ & $7.532 \mathrm{E}-03$ & $7.532 \mathrm{E}-04$ \\
\hline $1,2,3,7,8-\mathrm{PeCDF}$ & 0.05 & 0.973 & 0.049 & 0.282 & 0.014 & 0.749 & 0.037 \\
\hline $2,3,4,7,8-\mathrm{PeCDF}$ & 0.5 & $5.621 \mathrm{E}-03$ & $2.810 \mathrm{E}-03$ & 0.071 & 0.035 & 0.028 & 0.014 \\
\hline $1,2,3,4,7,8-\mathrm{HxCDF}$ & 0.1 & 0.238 & 0.024 & 0.342 & 0.034 & 0.201 & 0.020 \\
\hline $1,2,3,6,7,8-\mathrm{HxCDF}$ & 0.1 & $6.791 \mathrm{E}-03$ & $6.791 \mathrm{E}-04$ & 0.108 & 0.011 & 0.127 & 0.013 \\
\hline $1,2,3,7,8,9-\mathrm{HxCDF}$ & 0.1 & 4.039 & 0.404 & $1.735 \mathrm{E}-03$ & $1.735 \mathrm{E}-04$ & $1.803 \mathrm{E}-03$ & $1.803 \mathrm{E}-04$ \\
\hline $2,3,4,6,7,8-\mathrm{HxCDF}$ & 0.1 & $3.916 \mathrm{E}-04$ & $3.916 \mathrm{E}-05$ & 0.158 & 0.016 & 0.340 & 0.034 \\
\hline $1,2,3,4,6,7,8-\mathrm{HpCDF}$ & 0.01 & 0.110 & $1.100 \mathrm{E}-03$ & 0.958 & $9.580 \mathrm{E}-03$ & 6.019 & 0.060 \\
\hline $1,2,3,4,7,8,9-\mathrm{HpCDF}$ & 0.01 & $2.019 \mathrm{E}-03$ & $2.019 \mathrm{E}-05$ & 0.066 & $6.600 \mathrm{E}-04$ & 0.063 & $6.301 \mathrm{E}-04$ \\
\hline OCDF & 0.001 & 0.191 & $1.914 \mathrm{E}-04$ & 1.241 & $1.241 \mathrm{E}-03$ & 0.061 & $6.086 \mathrm{E}-05$ \\
\hline $\mathrm{TEQ}_{\mathrm{cal}}$ & & & 1.299 & & 0.918 & & 0.389 \\
\hline
\end{tabular}

$I_{0}=600 \mu \mathrm{W} \mathrm{cm}{ }^{-2}, C_{0}=20 \mathrm{mgl}^{-1}$.

upon driving away the photogenerated electron to the counter electrode by the external circuit, the survivability of photogenerated holes increased and thus the efficiency of the oxidation process improved.

\subsection{Removal of acute toxicity by photoelectrocatalysis, direct photolysis, and photocatalysis}

Comparison of the results of the bioluminescence test with those of the PCP residue analysis revealed that they exhibited quite similar trends. The acute toxicity decreased as the concentration of PCP decreased. Probably, PCP residue accounted for most of the acute toxicity of the samples. These results are not sufficient for making firm conclusions because a realistic ecotoxicological evaluation for chemicals necessitates more organism species and more toxicity indicators. Whereas luminescent bioassay results have been found showing good correlations with those of various other common bioassays with organisms of different trophic levels, including protozoa, fish, frogs, etc. (Kaiser and Palibrica, 1991). Thus, it seems that the photoelectrocatalysis process for the degradation of PCP did not generate significant levels of acutely toxic intermediates and could be used safely without concern for the final production of acutely toxic intermediates. Moreover, photoelectrocatalysis is safer than the direct photolysis and the photocatalysis process, since the reaction products from this process were less acutely toxic than those from the other two.

\subsection{Formation of dioxin-like chemicals in the photoelectrocatalysis process of $\mathrm{PCP}$}

PCP was proved unable to induce EROD activity in this bioassay (data not shown); hence the EROD activity induction of the initial solution should has been caused by other EROD-active compounds. The obvious increase of EROD activity of the samples at the former reaction stage suggested the formation of dioxin-like chemicals in the photoelectrocatalysis reaction of PCP. Therefore, it should be noted that the photoelectrocatalysis process of PCP could pose risk to the ecosystem although a high removal of PCP has been achieved and an uncritical use of this method should be avoided. On the other hand, the decrease of EROD activity during the latter stage of the reaction illustrated that the photoelectrocatalysis process was capable of removing the EROD inducers formed and as long as reaction time is sufficient the dioxin-like chemicals could be completely removed.

Reaction solutions in direct photolytic and photocatalytic process were more potent to induce EROD activity under given reaction condition. That is to say, photoelectrocatalysis was more efficient in the control of dioxin-like chemicals formation under specific condition.

The dioxins at low dose level in this study were difficult to be detected in the acute toxicity test and routine instrumental analysis while the HRGC/HRMS analysis for dioxin congeners is always costly and time consuming. Therefore, the target compound residue analysis and the acute toxicity test were necessary but not sufficient for the 
characterization of the treatment process. The EROD induction bioassay used in this study was a valuable method for indicating the presence of low dose dioxins since H4-IIE rat hepatoma cell is sensitive to P4501A (CYP1A) induction, an $\mathrm{Ah}$ receptor-mediated response that is associated with many of biochemical and toxic effects of $\mathrm{PCDD} / \mathrm{Fs}$. Furthermore, cytochrome P450 (CYP) induction is considered to be one of the most early biochemical cellular responses and represents a sensitive indicator of the potentially chronic harmful effects of chemicals (Denison and Whitlock, 1995). Accordingly, this EROD induction bioassay can be used as a prescreening method for the toxic potential of complex mixture and be applied to the evaluation for the environmental safety of a treatment process.

\subsection{Formation of PCDD/Fs in the photoelectrocatalysis process of $P C P$}

PCDD/Fs identified by HRGC-MS in the reaction mixture could at least partly answer for the EROD induction activity of the reaction system. OCDD was in the highest concentration level among the PCDD/Fs congeners. This result was similar to several other studies in which OCDD was reported to be the main dioxin congener formed in the direct photolytic process of PCP (Liu et al., 2002; Vollmuth et al., 1994). So PCP seemed to form OCDD readily in both direct photolytic process and the photoelectrocatalytic process. But OCDD would not be the major problem when controlling the $\mathrm{PCDD} / \mathrm{Fs}$ formation in this process despite of its high yield due to its low toxicity. Whereas $1,2,3,4,7,8-\mathrm{HxCDD}$ was in the highest toxicity level among the congeners.

OCDD could be produced by the dimerization of the reaction intermediates derived from PCP. Then the dechlorination of OCDD could yield a variety of PCDDs of decreasing chlorine content, which was partly an explanation for the formation of lower-chlorinated PCDD/Fs and the loss of OCDD. Other reaction pathways may also be involved. For example, lower-chlorinated chlorophenol could be formed as the dechlorination products of PCP (Jardim et al., 1997), condensation of which could result to $\mathrm{OCDD} / \mathrm{F}$ and lower-chlorinated PCDD/Fs.

The fact that PCDD/Fs could be removed efficiently by photoelectrocatalysis was exciting due to the extreme toxicity and persistence of dioxins. Photoelectrocatalysis process maybe an alternative method to remove these compounds in wastewater owing to its superior oxidation efficiency.

It can be seen that the PCDD/Fs could not completely answer for the EROD induction. The main reason may be that results from the bioassay integrated the biological effects of complex mixtures while calculating methods for TEQ assumed that the combined toxic effects of the components of a mixture are additive and it only deals with a limited number of compounds. In addition, it could not be excluded that other dioxin-like products besides PCDD/
Fs formed in the photoelectrocatalysis process of PCP. Thus, further investigation is needed to ensure the environmental safety of this process although the putative products may not be so dangerous as PCDD/Fs. Anyhow, $\mathrm{TEQ}_{\text {bio }}$ and $\mathrm{TEQ}_{\mathrm{cal}}$ showed similar trend in the latter reaction stage when both of them significantly decreased which confirmed the effective removal of $\mathrm{PCDD} / \mathrm{Fs}$ by photoelectrocatalysis.

\subsection{Effect of reaction conditions on the removal of $P C P$ and toxicity}

Significant differences of PCP and toxicity removal were observed under different reaction conditions. Similar observations that degradation rate of target compound increased with increasing light intensity and decreased with increasing initial concentration within a certain range have been reported in the photocatalytic reaction of dyes and chlorophenols (Carneiro et al., 2004; Nogueira and Guimarães, 2000). However, little attention was paid on the effect of reaction conditions on the toxicity of the intermediates. Results in this study showed that lower oxidation efficiency under low light intensity or high initial PCP concentration resulted in the formation of more toxic intermediates that were able to induce EROD. It should be noted that $\mathrm{TEQ}_{\text {bio }}$ of the samples kept increasing under lower light intensity or higher initial PCP concentration and the products were even more potent to inducing EROD activity than products from direct photolysis and photocatalysis of PCP. That is to say, photoelectrocatalysis was superior to direct photolysis and photocatalysis depending on reaction conditions. Hence, the cautious and precise control on the reaction conditions is crucial for the application of photoelectrocatalysis. At the same time, it may be possible in the treatment system to exert control over reaction products toxicity by appropriate control over reaction conditions since reaction conditions affected the reaction products from a given parent compound.

\section{Conclusion}

The bioassay combined with chemical analysis employed in this study was time- and cost-effective and could be applied to the evaluation for the environmental safety of the photoelectrocatalysis process to remove organic contaminants in wastewater. The target compound PCP could be effectively removed in the photoelectrocatalysis process while it seemed that the process did not generate significant levels of acutely toxic intermediates. The in vitro EROD induction test disclosed the potential risk caused by the formation of dioxin-like chemicals. Chemical analysis identified OCDD as the main dioxin product of PCP, while many other lower-chlorinated PCDD/Fs were also detected. Photoelectrocatalysis exhibited potential applicability since dioxins could be efficiently removed in the system. Moreover, photoelectrocatalysis was superior to direct photolysis and photocatalysis for both PCP removal 
and reduction in toxicity, although the reaction conditions should be under strict control.

\section{Funding sources}

National Nature Science Foundation of China (No. 20337020), National Basic Research Program of China (No. 2003CB415006), and National Science Fund for Distinguished Young Scholars (No. 20525723).

\section{Assurance}

Any studies involving humans or experimental animals were conducted in accordance with national and institutional guidelines for the protection of human subjects and animal welfare.

\section{Acknowledgments}

We thank National Nature Science Foundation of China (No. 20337020), National Basic Research Program of China (No. 2003CB415006), and National Science Fund for Distinguished Young Scholars (No. 20525723) for financial support. We also thank Prof. Ji-Ping Chen (Dalian Institute of Chemical Physics, Chinese Academy of Sciences, China) for his help with the chemical analysis for dioxins.

\section{References}

Bradford, M.M., 1976. A rapid and sensitive method for the quantification of microgram quantities of protein utilizing the principle of protein-dye binding. Anal. Biochem. 72, 248-254.

Carneiro, P.A., Osugi, M.E., Sene, J.J., Anderson, M.A., Zanoni, M.V.B., 2004. Evaluation of color removal and degradation of a reactive textile azo dye on nanoporous $\mathrm{TiO}_{2}$ thin-film electrodes. Electrochim. Acta $49,3807-3820$.

Crittenden, J.C., Liu, J.B., Hand, D.W., Perram, D.L., 1997. Photocatalytic oxidation of chlorinated hydrocarbons in water. Water Res. 31, 429-438.

Denison, M.S., Whitlock, J.P., 1995. Xenobiotic-inducible transcription of cytochrome P450 genes. J. Biol. Chem. 270, 18175-18178.

Deuttches Institut für Normung, 1997. German standard methods for the examination of water, wastewater and sludge. Bio-assays (group L) Part-34. Determination of the inhibitory effect of waste water on the light emission of Photobacterium phosphoreum; luminescent bacteria wastewater test using conserved bacteria, DIN 38412-34.

Donato, M.T., Gómez-Lechón, M.J., Castell, J.V., 1993. A microassay for measuring cytochrome P4501A1 and P450IIB1 activities in intact human and rat hepatocytes cultured on 96-well plates. Anal. Biochem. $213,29-33$

Hilscherova, K., Machala, M., Kannan, K., Blankenship, A.L., Giesy, J.P., 2000. Cell bioassays for detection of aryl hydrocarbon (AhR) and estrogen receptor (ER) mediated activity in environmental samples. Environ. Sci. Pollut. Res. 7, 159-171.

Ho, T.L., Bolton, J.R., 1998. Toxicity changes during the UV treatment of pentachlorophenol in dilute aqueous solution. Wat. Res. 32, 489-497.

ISO 11348-2, 1994. Water quality-determination of the inhibitory effect of water samples on the light emission of Vibrio fischeri (luminescent bacteria test) (revised version). Draft, Geneva, Switzerland.
Jardim, W.F., Moraes, S.G., Takiyama, M.M.K., 1997. Photocatalytic degradation of aromatic chlorinated compounds using $\mathrm{TiO}_{2}$ : toxicity of intermediates. Water Res. 31, 1728-1732.

Kaiser, K.L.E., Palibrica, V.S., 1991. Photobacterium phosphoreumtoxicity data index. Water Pollut. Res. J. Canada 26, 361-431.

Keith, L.H., Telliard, W.A., 1979. Priority pollutants: I-a perspective view. Environ. Sci. Technol. 13, 416-423.

Kim, D.H., Anderson, M.A., 1994. Photoelectrocatalytic degradation of formic acid using a porous $\mathrm{TiO}_{2}$ thin-film electrode. Environ. Sci. Technol. 28, 479-483.

Köhler, A., Hellweg, S., Escher, B.I., Hungerbühler, K., 2006. Organic pollutant removal versus toxicity reduction in industrial wastewater treatment: the example of wastewater from fluorescent whitening agent production. Environ. Sci. Technol. 40, 3395-3401.

Lamparski, L.L., Stehl, R.H., Johnson, R.L., 1980. Photolysis of pentachlorophenol-treated wood. Chlorinated dibenzo-p-dioxin formation. Environ. Sci. Technol. 14, 196-200.

Liu, P.Y., Zheng, M.H., Xu, X.B., 2002. Phototransformation of polychlorinated dibenzo- $p$-dioxins from photolysis of pentachlorophenol on soils surface. Chemosphere 46, 1191-1193.

Ma, M., Li, J., Wang, Z.J., 2005. Assessing the detoxication efficiencies of wastewater treatment processes using a battery of bioassays/biomarkers. Arch. Environ. Contam. Toxicol. 49, 480-487.

Manilal, V.B., Haridas, A., Alexander, R., Surender, G.D., 1992. Photocatalytic treatment of toxic organics in wastewater: toxicity of photodegradation products. Water Res. 26, 1035-1038.

NATO/CCMS (North Atlantic Treaty Organization, Committee on the Challenges of Modern Society), 1988. Scientific basis for the development of the International Toxicity Equivalency Factor (I-TEF) method of risk assessment for complex mixtures of dioxins and related compounds. Report No. 178.

Ni, Y.W., Zhang, Z.P., Zhang, Q., Chen, J.P., Wu, Y.N., Liang, X.M., 2005. Distribution patterns of $\mathrm{PCDD} / \mathrm{Fs}$ in chlorinated chemicals. Chemosphere 60, 779-784.

Nogueira, R.F.P., Guimarães, J.R., 2000. Photodegradation of dichloroacetic acid and 2,4-dichlorophenol by ferrioxalate $\mathrm{H}_{2} \mathrm{O}_{2}$ system. Water Res. 34, 895-901.

Pfeiffer, C.D., Nestrick, T.J., Kocher, C.W., 1978. Determination of chlorinated dibenzo- $p$-dioxins in purified pentachlorophenol by liquid chromatography. Anal. Chem. 50, 800-804.

Pintar, A., Besson, M., Gallezot, P., Gibert, J., Martin, D., 2004. Toxicity to Daphnia magna and Vibrio fischeri of kraft bleach plant effluents treated by catalytic wet-air oxidation. Water Res. 38, 289-300.

Qiao, M., Chen, Y.Y., Zhang, Q.H., Huang, S.B., Ma, M., Wang, C.X., Wang, Z.J., 2006. Identification of Ah receptor agonists in sediment of Meiliang Bay, Taihu Lake, China. Environ. Sci. Technol. 40, $1415-1419$.

Quan, X., Yang, S.G., Ruan, X.L., Zhao, H.M., 2005. Preparation of titania nanotubes and their environmental applications as electrode. Environ. Sci. Technol. 39, 3770-3775.

US Environmental Protection Agency, Method 1613, 1994. Tetra-through octa-chlorinated dioxins and furans by isotope dilution HRGC/ HRMS. EPA 821-B-94-005, Revision B.

Vinodgopal, K., Hotchandani, S., Kamat, P.V., 1993. Electrochemically assisted photocatalysis. $\mathrm{TiO}_{2}$ particulate film electrodes for photocatalytic degradation of 4-chlorophenol. J. Phys. Chem. 97, 9040-9044.

Vollmuth, S., Zajc, A., Niessner, R., 1994. Formation of polychlorinated dibenzo-p-dioxins and polychlorinated dibenzofurans during the photolysis of pentachlorophenol-containing water. Environ. Sci. Technol. 28, 1145-1149.

Wang, C.X., Yediler, A., Lienert, D., Wang, Z.J., Kettrup, A., 2002. Toxicity evaluation of reactive dyestuffs, auxiliaries and selected effluents in textile finishing industry to luminescent bacteria Vibrio fishcheri. Chemosphere 46, 339-344. 